\title{
Dehydroepiandrosterone in relation to other adrenal hormones during an acute inflammatory stressful disease state compared with chronic inflammatory disease: role of interleukin- 6 and tumour necrosis factor
}

\author{
Rainer H Straub, Karin Lehle, Hans Herfarth ${ }^{1}$, Markus Weber, Werner Falk, Jürgen Preuner and \\ Jürgen Schölmerich ${ }^{1}$ \\ Department of Internal Medicine I and ${ }^{1}$ Department of Cardiothoracic Surgery, University Hospital Regensburg, 93042 Regensburg, Germany \\ (Correspondence should be addressed to R H Straub, Laboratory of Neuroendocrinoimmunology, Department of Internal Medicine I, \\ University Hospital Regensburg, 93042 Regensburg, Germany; Email: rainer.straub@klinik.uni-regensburg.de)
}

\begin{abstract}
Objective: Serum levels of dehydroepiandrosterone (DHEA) and DHEA sulphate (DHEAS) are low in chronic inflammatory diseases, although the reasons are unexplained. Furthermore, the behaviour of serum levels of these hormones during an acute inflammatory stressful disease state is not well known.

Subjects and methods: In this study in patients with an acute inflammatory stressful disease state (13 patients undergoing cardiothoracic surgery) and patients with chronic inflammation (61 patients with inflammatory bowel diseases (IBD)) vs 120 controls, we aimed to investigate adrenal hormone shifts looking at serum levels of DHEA in relation to other adrenal hormones. Furthermore, we tested the predictive role of serum tumour necrosis factor (TNF) and interleukin-6 (IL-6) for a change of serum levels of DHEA in relation to other adrenal hormones.

Results: The molar ratio of serum levels of DHEA/androstenedione (ASD) was increased in patients with an acute inflammatory stressful disease state and was decreased in patients with chronic inflammation. The molar ratio of serum levels of DHEAS/DHEA was reduced during an acute inflammatory stressful disease state and was increased in patients with chronic inflammation. A multiple linear regression analysis revealed that elevated serum levels of TNF were associated with a high ratio of serum levels of DHEA/ASD in all groups (for IL-6 in patients with an acute inflammatory stressful disease state only), and, similarly, elevated serum levels of TNF were associated with a high ratio of serum levels of DHEAS/DHEA only in IBD (for IL-6 only in healthy subjects).

Conclusions: This study indicates that changes of serum levels of DHEA in relation to serum levels of other adrenal hormones are completely different in patients with an acute inflammatory stressful disease state compared with patients with chronic inflammation. The decrease of serum levels of DHEAS and DHEA is typical for chronic inflammation and TNF and IL-6 play a predictive role for these changes.
\end{abstract}

European Journal of Endocrinology 146 365-374

\section{Introduction}

Chronic inflammatory diseases such as inflammatory bowel diseases (IBD), rheumatoid arthritis, systemic lupus erythematosus, progressive systemic sclerosis and pemphigus are characterised by a profound decrease of serum levels of adrenal androgens (1-6). In various chronic inflammatory diseases, we and others have observed a shift to cortisol in relation to dehydroepiandrosterone (DHEA) and DHEA sulphate (DHEAS) (5, 7-11). Even short-term inflammation due to cholestasis over 5-12 days induced a profound shift to cortisol in relation to adrenal androgens (12). Thus, concerning shifts of adrenal hormones, chronic IBD may be a representative model for chronic inflammatory diseases. Interestingly, very similar findings can be observed in patients with long-term disease states such as HIV or syphilis infection $(13,14)$ or chronic heart failure (15), or in patients on intensive care units (reviewed in (16)). During an acute inflammatory response, one would expect a parallel increase of serum levels of aldosterone, cortisol and adrenal androgens due to an increase of the serum levels of the stimulating adrenocorticotrophic hormone $(17,18)$. The reason for 
the unexpected decrease of serum levels of adrenal androgens during chronic inflammation is not known. However, a decrease of serum levels of adrenal androgens may lead to a more proinflammatory disease state because DHEA has been shown to inhibit proinflammatory cytokines such as secretion of tumour necrosis factor (TNF) $(19-23)$. On the other hand, DHEA seems to favour T-helper lymphocyte type (Th) 1 reactions whereas DHEA inhibits Th2 immune responses (24). Thus, DHEA may exert an anti-inflammatory effect in Th2-driven diseases and a proinflammatory effect in Th1-driven diseases.

Steroidogenesis in the human adrenal gland consists of three major pathways: (i) mineralocorticoid production (end point aldosterone), (ii) glucocorticoid production (end point cortisol), and (iii) androgen production (end point DHEA, DHEAS and androstenedione (ASD)). The physiological roles of mineralocorticoids and glucocorticoids are well known; however, the role of adrenal androgens is currently under investigation. DHEAS is secreted in large amounts from the adrenal glands (90\% of DHEAS is from the adrenal glands) (25), reflecting the adrenal production of its precursor DHEA (25). DHEAS per se has no effect, but after conversion to the biologically active DHEA in peripheral tissues, the hormone is intracellularly processed, yielding active metabolites such as testosterone and oestrogens $(26,27)$. As DHEAS is linearly interconverted to DHEA (28), DHEAS is the hormone pool of DHEA and is a stable serum marker for DHEA availability. In the case of decreased DHEAS serum levels, the active hormone DHEA will also decrease. DHEA is converted to ASD by the $3 \beta$-hydroxysteroid dehydrogenase (3 $\beta$-HSD) (25). ASD is an important precursor of testosterone in the follicular phase of the menstrual cycle and in postmenopausal women (25). In men, DHEA and ASD account for a significant part of testosterone in aged subjects when the testicular production is markedly decreased (25). Thus, adrenal androgens play an important role in women and men when gonadal glands undergo gradual aged-related involution. In recent years, the importance of DHEA substitution has been investigated in studies in chronic diseases such as ulcerative colitis (UC) (29), systemic lupus erythematosus $(30,31)$ and adrenal insufficiency (32, 33). The positive effect of DHEA has been demonstrated as a reduction of disease activity $(29,30)$, increase of bone mineral density $(34,35)$, and an improvement of well-being and mental health (32). Thus, the third major route of adrenal steroidogenesis - androgen production - may be important in inflammatory diseases due to immunomodulatory properties of DHEA or downstream hormones.

At the moment, the mechanisms for the loss of DHEA and DHEAS in chronic inflammatory diseases is mysterious. Furthermore, the behaviour of serum levels of these hormones in relation to cytokines in patients with an acute inflammatory stressful disease state is uncertain. In this study, we aimed to investigate DHEA hormone shifts in order to focus on distinct steroidogenic enzymes using serum levels of DHEA relative to serum levels of other adrenal hormones in patients with an acute inflammatory stressful disease state compared with patients with chronic inflammation (patients with IBD in an active and an inactive state of the disease). For the acute inflammatory stressful disease state, we used the model of cardiothoracic surgery because the induction of an operation is a strong stimulus for cytokine production and for activation of the systemic stress axes. Cytokine production is mainly due to the intense trauma of skin, muscles and bone with a consecutive activation of the immune system $(36,37)$. Activation of the hypothalamic-pituitary-adrenal axis and the hypothalamus-autonomic nervous system axis is due to psychological stress, cytokine release and general anaesthesia (38-40). We compared these data with age-matched and sex-matched healthy subjects (HSs). In particular, the following two hormone ratios were studied: serum levels of DHEA/DHEAS (for the sulphatase and sulphotransferase) and serum levels of DHEA/ASD (3 $\beta$-HSD). Since interleukin-6 (IL-6) and TNF may play a role in modulation of steroidogenesis, we investigated whether serum levels of these cytokines can predict changes of these particular ratios.

\section{Subjects and methods}

\section{HSs}

One hundred and twenty Caucasian subjects were recruited (mean age $43.8 \pm 2.1$ (s.E.M.) years), and health status was verified by means of a 33-item questionnaire. Serum levels of DHEA and DHEAS of these HSs were presented in an earlier study in another context (41). The questionnaire addressed known diseases in the past and at present, current symptoms of diseases, current medication, prior vaccination, alcohol intake, smoking habits, family history and surgical history. The questionnaire was adapted to the SENIEUR protocol (42). Our protocol established strict admission criteria for immunogerontological studies in man based on clinical information. Sixty were men and 60 were women (ten men and ten women for each decade: $15-24, \quad 25-34, \quad 35-44,45-54, \quad 55-64, \quad 65-80$ years). Fertile women were not taking contraceptives. Blood was drawn between 1000 and $1200 \mathrm{~h}$, and serum and plasma were immediately stored at $-80^{\circ} \mathrm{C}$ in adequate aliquots. Collection of these blood samples lasted about 2 years due to the strict inclusion criteria. All subjects gave written consent for further investigation of blood samples. Data of 40 men and 41 women (mean age $34.9 \pm 1.2$ years) were used in an age-matched and sex-matched comparison with IBD patients. 


\section{Patients with an acute inflammatory stressful disease state}

Thirteen patients undergoing elective cardiothoracic surgery due to coronary revascularisation were investigated (mean age 58.5 \pm 1.1 years; female/male 2/11). We used these patients because a strong immune response with pronounced elevation of IL-6 and TNF was expected. The experimental procedure was approved by the Ethical Committee of the University of Regensburg. These patients were in good condition and had apparently no infection or other condition prior to the operation which would have excluded them from surgery. All patients had a good outcome during the operation and 5 days thereafter. Blood samples were drawn before surgery $(0 \mathrm{~h})$, at 6 and $18 \mathrm{~h}$ after the start of the operation (start at 0800-0900h). Serum and plasma were frozen in adequate aliquots and stored at $-80^{\circ} \mathrm{C}$. These patients received the following drugs prior to operation: nitrates $(n=10), \beta$-adrenoceptor antagonists $(n=8)$, hydroxymethylglutaryl coenzyme A reductase inhibitor $(n=7)$, angiotensin-converting enzyme inhibitor $(n=6)$, calcium antagonist $(n=5)$, diuretics $(n=3)$, heparin $(n=2)$, allopurinol $(n=1)$, ranitidine $(n=1)$, thyroxine $(n=1)$ and amoxicillin $(n=1)$.

\section{Patients with chronic inflammatory diseases}

Forty patients with Crohn's disease (CD) and 21 patients with UC without prior glucocorticoid treatment in an active and inactive disease state were included (CD: age, mean \pm s.E.M., $32.0 \pm 2.2$ years, disease duration $8.2 \pm 1.1$ years, female/male $21 / 19$; UC: $38.6 \pm 3.7$ years, $5.7 \pm 0.8$ years, $14 / 7)$. Furthermore, some of these patients received budesonide (CD three, UC three), sulphasalazine ( $\mathrm{CD}$ one, $\mathrm{UC}$ two) or 5-amino salicylic acid (CD 18, UC 8), and none was administered azathioprine. These patients were referred to the participating teaching hospital. All patients were clinically evaluated by a gastroenterologist, and disease activity in patients with $\mathrm{CD}$ was assessed using the $\mathrm{CD}$ activity index (CDAI) (43), and in patients with UC with the Rachmilewitz index (RI) (44). Patients with a $\mathrm{CDAI} \leq 150$ and an $\mathrm{RI} \leq 5$ were classified to have inactive disease, whereas patients with CDAI $>150$ or RI $>5$ were considered to have active disease. Blood samples were drawn between 0900 and $1100 \mathrm{~h}$ at two separate visits, when disease activity at the visit was either low or high (mean time interval between the two visits: CD 5.2 \pm 1.0 months, UC $3.9 \pm 0.9$ months).

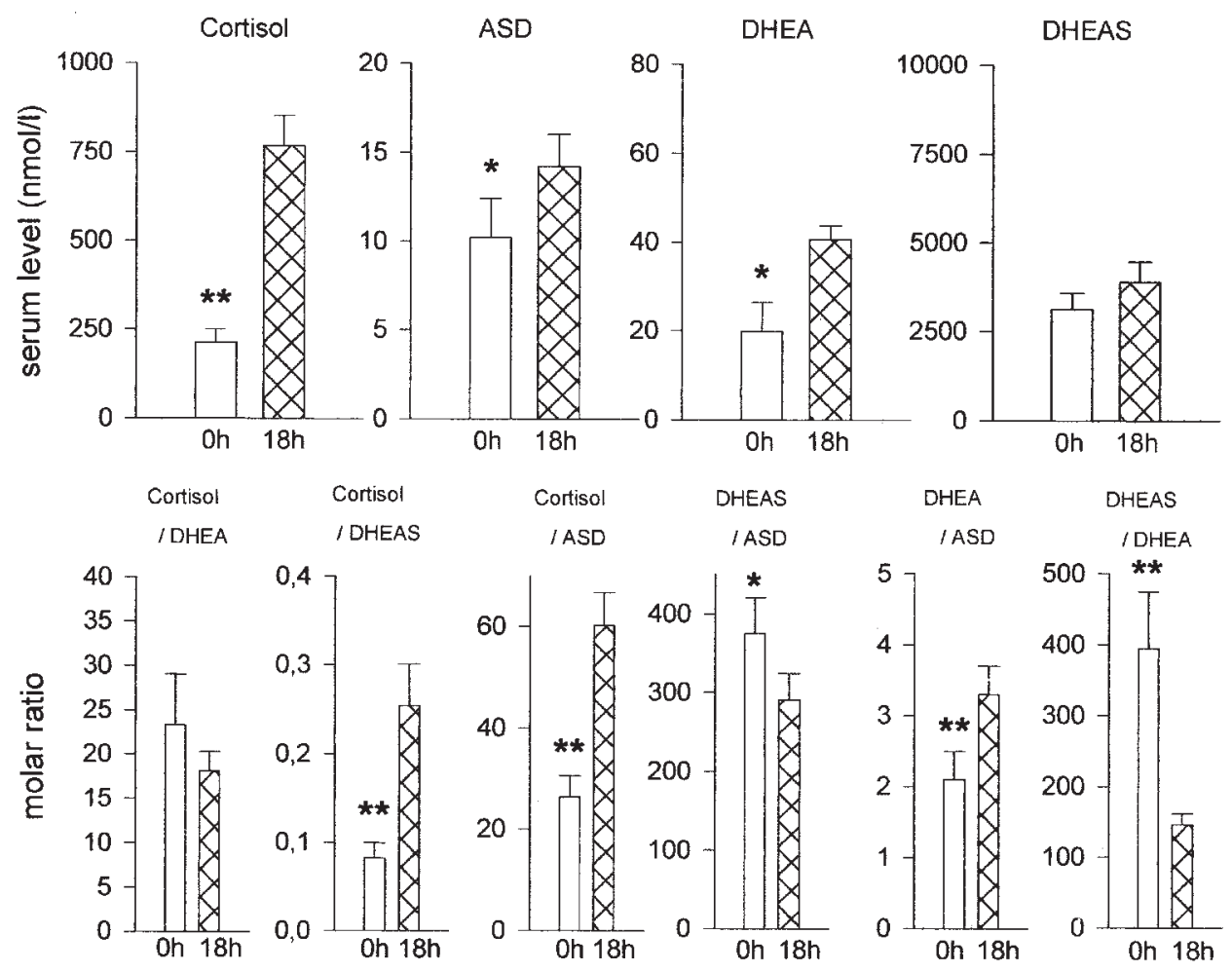

Figure 1 Change of serum levels of adrenal hormones and ratios of serum levels of hormones before and $18 \mathrm{~h}$ after the beginning of cardiothoracic surgery in patients who required coronary revascularisation (model of an acute inflammatory stressful disease state). Open bars indicate baseline values (before surgery), and cross-hatched bars represent values $18 \mathrm{~h}$ after the beginning of surgery (on the intensive care unit). Serum hormones were measured by RIA or ELISA. ${ }^{\star} P<0.05,{ }^{* \star} P<0.01$ for the difference between baseline and $18 \mathrm{~h}$ later. 


\section{Laboratory parameters}

We used IRMA assays for the quantitative determination of serum levels of cortisol (Coulter Immunotech, Marseilles, France; detection limit $10 \mathrm{nmol} / \mathrm{l}$ ) and ASD (DPC Biermann, Bad Nauheim, Germany; detection limit $0.14 \mathrm{nmol} / \mathrm{l}$ ). Serum levels of DHEAS (IBL, Hamburg, Germany; detection limit $0.13 \mu \mathrm{mol} / \mathrm{l}$ ), DHEA (Diagnostic Systems Laboratory, Webster, TX, USA; detection limit $0.13 \mathrm{nmol} / \mathrm{l}$ ), IL-6 (high sensitivity Quantikine; R\&D Systems, Minneapolis, MN, USA; detection limit $0.2 \mathrm{pg} / \mathrm{ml}$ ) and TNF (high sensitivity Quantikine; R\&D Systems; detection limit $0.2 \mathrm{pg} / \mathrm{ml}$ ) were measured by means of immunometric enzyme immunoassays. Intra-assay and interassay coefficients of variation were below $10 \%$ in each test.

\section{Statistical analysis}

In order to assess the statistical significance of differences between values assessed at different time points in subjects with the acute inflammatory stressful disease state the non-parametrical Wilcoxon test for paired data was used (SPSS/PC for Windows, v.10.0.5; SPSS, Inc., Chicago, IL, USA). The same test was used for patients with CD and UC when comparing values assessed in the inactive and active disease state. Group medians in two different groups were compared by a Mann-Whitney signed rank test (SPSS). Multiple linear regression analysis was run to demonstrate the interrelation between an indicated hormone ratio (dependent variable) and serum levels of IL-6 and TNF (both were the independent variables) (SPSS). In the multiple linear regression analysis, the standardised regression coefficient beta $(\beta)$ was used to indicate the strength of the interrelation. $\beta$ represents the predicted increase of the dependent variable (expressed in standard deviation units of the dependent variable) that would be expected per standard deviation increase of the independent variables (lies between $-1 \leq$ $0 \leq 1)$. The proportion of the variation of the dependent variable is given, which can be explained by the regression model using the independent variables (derived from the squared correlation coefficient R). $P$-values of less than 0.05 were considered to be significant and means \pm S.E.M. are given.

\section{Results}

\section{Patients with an acute inflammatory stressful disease state}

In patients undergoing bypass surgery an acute inflammatory response of the adrenal glands $6-18 \mathrm{~h}$ after the start of surgery is observed (mean increase of serum levels of cytokines between 0 and $6 \mathrm{~h}$ for TNF $134 \mathrm{pg} / \mathrm{ml}$, and IL-6 $1300 \mathrm{pg} / \mathrm{ml}$; mean increase of serum levels of cytokines between 0 and $18 \mathrm{~h}$ for TNF $35 \mathrm{pg} / \mathrm{ml}$, and IL-6 $424 \mathrm{pg} / \mathrm{ml})$. Six and $18 \mathrm{~h}$ after the beginning of surgery, the operation led to a significant increase in serum levels of cortisol, ASD and DHEA but not of DHEAS (shown for $18 \mathrm{~h}$ in Fig. 1, upper panels). In these patients, serum levels of cortisol did not markedly change in relation to serum levels of DHEA (Fig. 1, lower panels). However, there was a strong increase of serum levels of cortisol in relation to serum levels of DHEAS and ASD (Fig. 1, lower panels). Furthermore, serum levels of DHEA significantly increased in relation to serum levels of ASD (Fig. 1, lower panels), and serum levels of DHEAS significantly decreased in relation to serum levels of DHEA (Fig. 1, lower panels). Thus, cardiothoracic surgery resulted in a relative increase of serum levels of DHEA and cortisol in relation to serum levels of ASD

Table 1 Multiple linear regression analysis of serum levels of IL-6 and TNF (independent variables) and ratios of serum levels of hormones (dependent variable) to evaluate hormonal changes in HSs, patients with an acute inflammatory stressful disease state, and patients with chronic IBD in an active and an inactive state of the disease.

\begin{tabular}{lll}
\hline & \multicolumn{1}{c}{ DHEA/ASD } & \multicolumn{1}{c}{ DHEAS/DHEA } \\
\hline HSs & TNF $(P<0.001)$ & $\begin{array}{l}\text { IL-6 }(P<0.001) \\
(\beta:+0.462)\end{array}$ \\
Acute inflammatory stressful disease state (cardiothoracic surgery) & $\begin{array}{l}(\beta:+0.720) \\
\text { TNF and IL-6 }(P<0.001)\end{array}$ & $\begin{array}{l}\text { No influence of TNF or IL-6 } \\
(\beta \text { for IL-6: }+0.751)\end{array}$ \\
& $(\beta$ for TNF: +0.269$)$ & \\
Chronic inflammation & & TNF $(P<0.001)$ \\
CD & TNF $(P=0.053)$ & $(\beta:+0.685)$ \\
Inactive & $(\beta:+0.308)$ & TNF $(P<0.001)$ \\
Active & TNF $(P<0.001)$ & $(\beta:+0.708)$ \\
UC & $(\beta:+0.451)$ & TNF $(P<0.001)$ \\
Inactive & & $(\beta:+0.712)$ \\
Active & TNF $(P=0.001)$ & TNF $(P<0.001)$ \\
& $(\beta:+0.533)$ & $(\beta:+0.793)$
\end{tabular}


or DHEAS (Fig. 1), but the relation of serum levels of cortisol to serum levels of DHEA remained stable.

In a multiple linear regression analysis, serum levels of IL- 6 measured at $6 \mathrm{~h}\left(\mathrm{IL}-6_{6 \mathrm{~h}}\right)$ together with serum levels of $\mathrm{TNF}_{6 \mathrm{~h}}$ as independent variables explained $83 \%\left(\mathrm{R}^{2}=0.83\right)$ of the variation of the ratio DHEA/ ASD at $18 \mathrm{~h}\left(\mathrm{DHEA}_{/} \mathrm{ASD}_{18 \mathrm{~h}}\right.$ ) (Table 1). This strongly indicates that the higher the serum levels of cytokines were the higher were the serum levels of DHEA in relation to $\mathrm{ASD}_{18 \mathrm{~h}}$, whereas the ratio of serum levels of DHEAS/DHEA $18 \mathrm{~h}$ could not be predicted by IL- $6_{6 \mathrm{~h}}$ and $\mathrm{TNF}_{6 \mathrm{~h}}$ (Table 1).

\section{Patients with chronic IBD}

In order to investigate patients with a long-standing, chronic inflammatory disease, patients with IBD were studied. CD and UC patients as compared with agematched and sex-matched HSs had elevated levels of serum cytokines such as IL-6 (CD active/inactive $32.7 \pm 9.2 / 17.5 \pm 6.1, \quad \mathrm{UC}$ active/inactive 22.4 $10.3 / 23.4 \pm 10.3$, HSs $1.6 \pm 0.1 \mathrm{pg} / \mathrm{ml}, P<0.01$ for the difference between both patient groups and HSs), and TNF (CD active/inactive 5.0 $\pm 0.4 / 4.4 \pm 0.3$, UC active/inactive $5.7 \pm 0.8 / 4.7 \pm 0.5$, HSs $1.8 \pm 0.1 \mathrm{pg} / \mathrm{ml}$, $P<0.01$ for the difference between both patient groups and HSs). Serum cortisol levels were similar in patients as compared with HSs although cytokine serum levels were significantly elevated (Figs 2 and 3, upper panels). Serum levels of ASD, DHEA and DHEAS were significantly lower as compared with age-matched and sex-matched HSs irrespective of disease activity (Figs 2 and 3, upper panels). In patients, serum cortisol levels were higher in relation to serum levels of DHEA and DHEAS irrespective of disease activity (Figs 2 and 3, lower panels). In patients, serum levels of cortisol were higher in relation to serum levels of ASD in active patients with CD (Fig. 2, lower panels) and all patients with UC (Fig. 3, lower panels). This indicates a marked shift in the direction of cortisol as compared with DHEA, DHEAS and ASD, particularly in patients with active disease. Furthermore, in these IBD patients, serum levels of DHEAS and DHEA were significantly lower in relation to serum levels of ASD irrespective of disease activity (Figs 2 and 3, lower panels). Serum levels of DHEAS were significantly higher in relation to serum levels of DHEA, which indicates a shift in the direction of DHEAS irrespective of disease activity (Figs 2 and 3, lower panels).

In the multiple linear regression analysis in patients with CD, serum levels of TNF explained 10\% (inactive

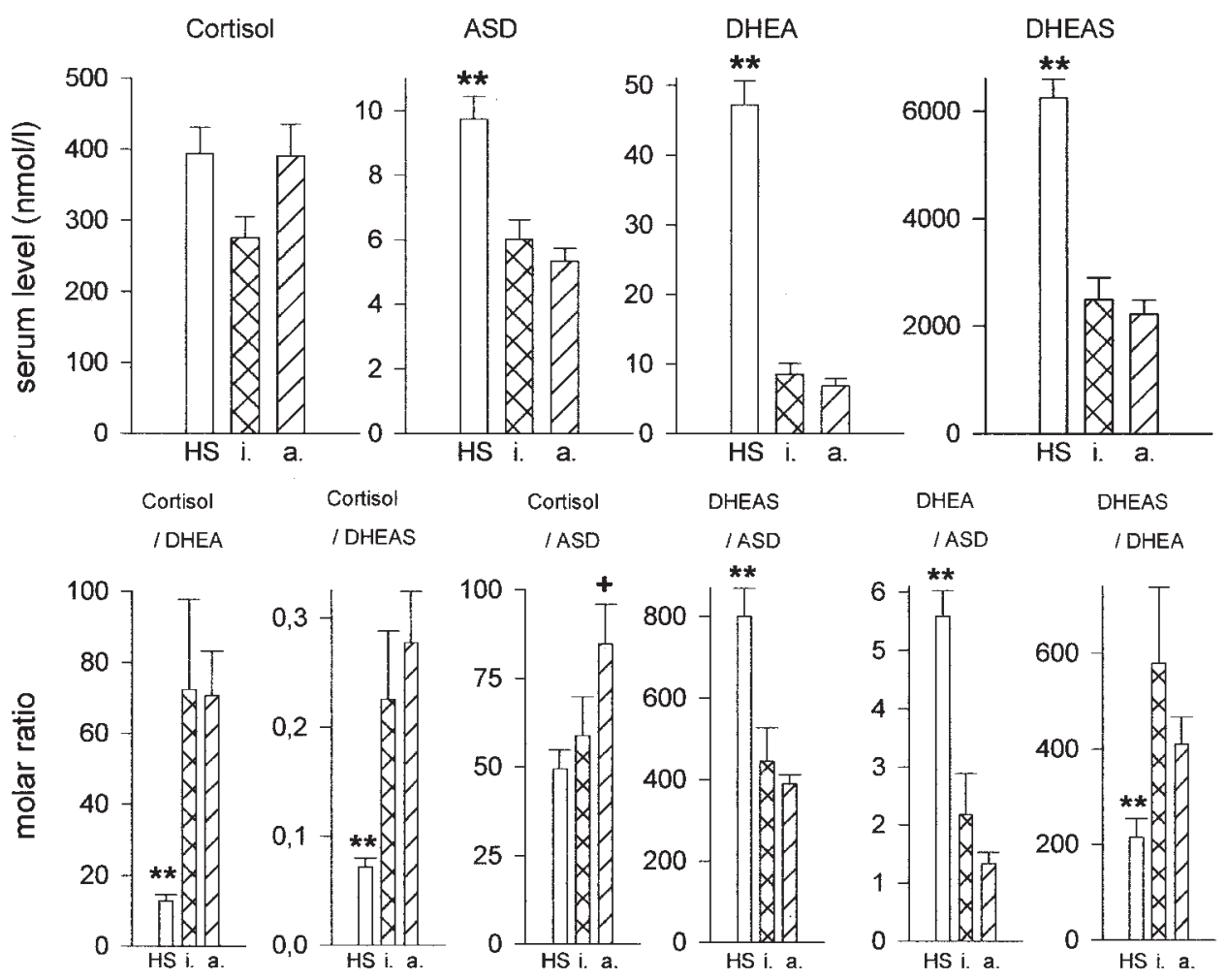

Figure 2 Serum levels of adrenal hormones and ratios of serum levels of hormones in HSs (open bars) and patients with inactive (cross-hatched bars) and active (hatched bars) CD (long-term chronic inflammation). $\mathrm{i}=$ inactive disease (CDAI $\leq 150), a=$ active disease $(\mathrm{CDAl}>150)$. ${ }^{\star} P<0.01$ for the difference between HSs and active/inactive patients with $\mathrm{CD}$. ${ }^{+} P<0.05$ for the difference between active patients with CD vs inactive patients with CD or HSs. 

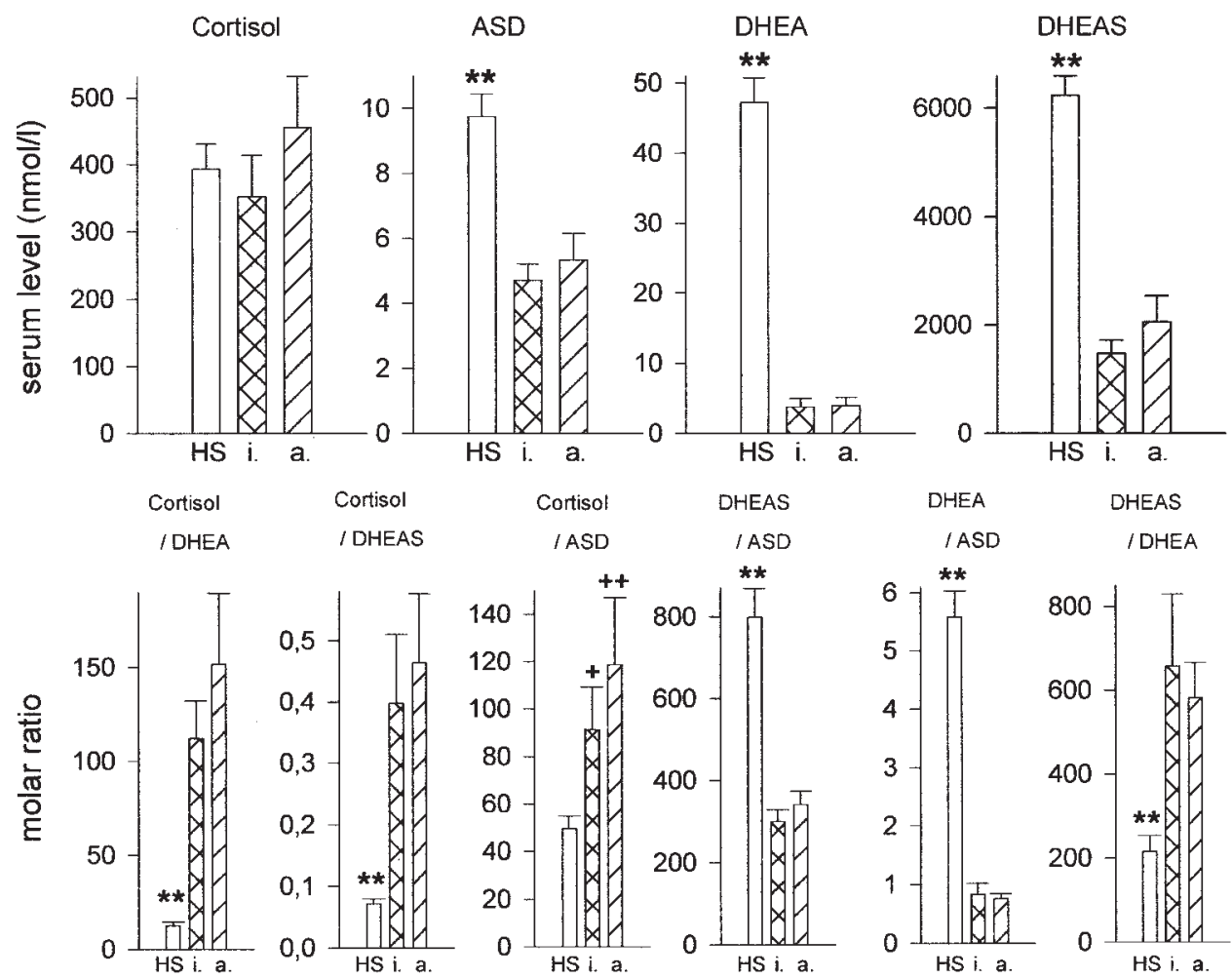

Figure 3 Serum levels of adrenal hormones and ratios of serum levels of hormones in HSs (open bars) and patients with inactive (cross-hatched bars) and active (hatched bars) UC (long-term chronic inflammation). $\mathrm{i}=$ inactive disease $(\mathrm{RI} \leq 5)$, $\mathrm{a}=$ active disease $(\mathrm{RI}>5) .{ }^{* *}<0.01$ for the difference between $\mathrm{HSs}$ and active/inactive patients with $\mathrm{UC} .{ }^{+} P<0.05,{ }^{++} P<0.01$ for the difference between active/inactive patients with UC and HSs.

healthy

subjects
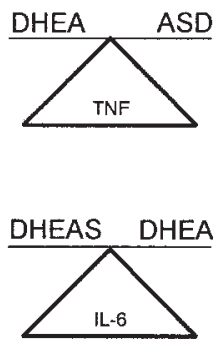

acute inflammation
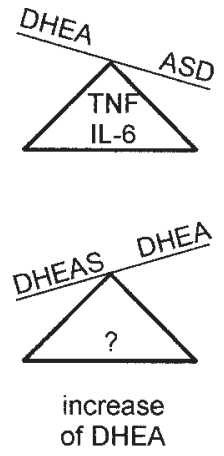

chronic inflammation
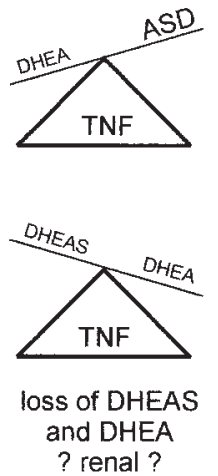

Figure 4 Changes of serum levels of DHEA in relation to serum levels of DHEAS or ASD. It is indicated that serum levels of DHEA are elevated relative to serum levels of DHEAS and ASD in an acute inflammatory stressful disease state, whereas it is the opposite situation in patients with chronic inflammatory disease. A possible renal loss of DHEAS would also lead to low serum levels of DHEAS and DHEA. As demonstrated by multiple linear regression analysis, TNF and in two situations IL-6 influence the hormonal balance $(?=$ modulators not known). A smaller font indicates a lower serum concentration of the hormone/cytokine.
$\mathrm{CD}$ ) and $51 \%$ (active $\mathrm{CD}$ ) of the variation of the ratio of serum levels of DHEA/ASD (Table 1). In patients with UC, serum levels of TNF explained 28\% (inactive) and $11 \%$ (active) of the variation of the ratio of serum levels of DHEA/ASD (Table 1). In another model, serum levels of TNF explained 47\% (inactive $\mathrm{CD}$ ) and $56 \%$ (active CD) of the variation of the ratio of serum levels of DHEAS/DHEA (Table 1). In patients with UC, serum levels of TNF explained 49\% (inactive) and $67 \%$ (active) of the variation of the ratio of serum levels of DHEAS/DHEA (Table 1). This clearly indicates that elevated serum levels of TNF were associated with high serum levels of DHEA in relation to ASD and, similarly, high serum levels of TNF were associated with high serum levels of DHEAS in relation to DHEA.

\section{Role of IL-6 and TNF for changes of DHEA in relation to other adrenal hormones in HSs}

In the multiple linear regression analysis of all $120 \mathrm{HSs}$, serum levels of TNF explained $60 \%$ of the variation of the ratio of serum levels of DHEA/ASD (Table 1). In contrast, serum levels of IL- 6 explained $27 \%$ of the variation of the ratio of serum levels of DHEAS/DHEA but 
serum levels of TNF did not play a role for this latter ratio (Table 1 ). In a separate analysis of female and male subjects, these interrelations remained highly significant (data not shown). This indicates that elevated serum levels of TNF were associated with high serum levels of DHEA in relation to ASD, and elevated serum levels of IL-6 were associated with high serum levels of DHEAS in relation to DHEA.

\section{Discussion}

This study compared the response of the adrenal glands in different inflammatory states (healthy, acute inflammatory stressful state, chronic inflammation). In the model of patients with an acute inflammatory stressful disease state with a marked increase of serum levels of TNF and IL-6, production of cortisol and DHEA is favoured in relation to ASD and DHEAS (Fig. 4). In this acute inflammatory situation, the anti-inflammatory properties of cortisol $(45,46)$ and DHEA $(19-23,47,48)$ are probably important to dampen inflammation in the periphery (49). Thus, presence of these hormones is crucial for termination of the acute inflammatory state. For cortisol, this has been demonstrated in endotoxin shock models because adrenalectomy significantly increased mortality in various animal models (50-52). Mortality was significantly reduced when these animals were treated with glucocorticoids (50-52). Furthermore, adrenalectomy sensitises mice to the lethal effects of IL- 1 and TNF (53). Thus, elevation of cortisol, at the expense of other adrenal hormones, will be of major importance in patients with an acute inflammatory stressful disease state. This is probably similar with respect to DHEA because it has been shown that DHEA can inhibit proinflammatory cytokines such as secretion of TNF (19-23). On the other hand, DHEA seems to favour Th1 reactions whereas DHEA inhibits Th2 immune responses (24). Thus, DHEA may exert an anti-inflammatory effect in Th2-driven diseases and a proinflammatory effect in Th1-driven diseases.

In the chronic inflammatory situation (here IBD), steroidogenesis is significantly changed, which always leads to severe reduction of serum levels of DHEAS, not only in patients with $\operatorname{IBD}(1-4,6,54)$. The reason for the reduction of serum levels of DHEAS and DHEA in chronic inflammatory diseases is not yet known. This present study demonstrates that the adrenal glands favour production of ASD and cortisol in relation to DHEA and DHEAS in chronic inflammatory diseases irrespective of disease activity, which is in contrast to patients with an acute inflammatory stressful disease state (Fig. 4). However, despite inflammation and elevated serum cytokine levels, serum cortisol levels of patients with IBD were similar as compared with HSs. Moreover, serum levels of ASD, DHEA and DHEAS were significantly lower in patients with IBD as compared with HSs. Low production of adrenal glucocorticoids and adrenal androgens in patients with IBD may be a significant risk factor for the perpetuation of these diseases because the antiinflammatory potential of these hormones or the downstream sex hormones is absent.

Furthermore, this study attempted to delineate a predictive role of serum TNF and serum IL-6 for changes of steroid hormone levels. The hypothesis that these cytokines play a role was derived from reports which demonstrated that TNF, IL-1 $\beta$, IL-6 and interferon- $\gamma$ modulate steps of steroidogenesis at several levels in vitro (55-62). In our study, serum levels of TNF were positively related to increased serum levels of DHEA in relation to ASD in HSs, patients with IBD, and in patients with an acute inflammatory stressful disease state (Table 1, Fig. 4). This role of TNF seems to be general irrespective of the study group (healthy, acute inflammatory state, chronic inflammation). TNF is present in the cortex of the normal adrenal gland $(63,64)$, and our data may indicate that this cytokine is important for regulation of steroidogenesis not only in acute/chronic inflammatory patients but even in HSs. At the moment, we do not know how TNF influences the ratio of the serum levels of DHEA/ASD in healthy or acute/chronic inflammatory patients. One can speculate that a direct influence of TNF on distinct enzyme steps such as DHEA/ASD or DHEAS/DHEA is also present in vivo.

In order to investigate the latter step of adrenal androgen production (i.e. DHEAS/DHEA), we considered the relative change of serum levels of DHEAS in relation to serum levels of DHEA. This step leads not only to activation of DHEA (DHEAS $\rightarrow$ DHEA using DHEAS sulphatase) but the conversion is also necessary to maintain the sex hormone pool in the periphery in the form of DHEAS (DHEA $\rightarrow$ DHEAS using DHEA sulphotransferase). Since DHEAS can be converted to DHEA in target organs such as macrophages, the DHEAS serum pool is important for the production of downstream steroid hormones in target organs in the periphery (26-28). DHEAS is much more stable as compared with DHEA (half life in blood: $4 \mathrm{~h}$ vs 20 min (28)) and serum concentrations are significantly higher $(5000 \mathrm{nmol} / \mathrm{l}$ vs $50 \mathrm{nmol} / \mathrm{l}$ (25)). Thus, reduction of the serum pool of DHEAS is a critical step for the overall reduction of DHEA and other downstream hormones in the periphery. We have now found that subjects with acute inflammation have lower serum levels of DHEAS in relation to serum levels of DHEA as compared with the situation before acute inflammation (Fig. 4). In contrast, patients with chronic inflammatory diseases demonstrated increased serum levels of DHEAS in relation to DHEA but these patients had overall significantly lower values as compared with age-matched and sex-matched HSs (Fig. 4). Since TNF was positively associated with the ratio of the serum levels of DHEAS/DHEA only in the chronic 
inflammatory disease, this particular cytokine can be responsible for an increase of serum levels of DHEAS in relation to serum levels of DHEA. Indeed, Hennebold \& Daynes (26) have shown that TNF inhibits the sulphatase in murine macrophages. It may be that the sulphatase reaction from DHEAS to DHEA is inhibited in the periphery, particularly in chronic inflammatory diseases. The question remains whether under these conditions renal excretion of serum DHEAS is increased leading to the low serum levels of DHEAS and consequently low serum levels of DHEA. Such a loss of DHEA due to increased renal excretion of DHEAS would also explain the changed ratio of serum levels of DHEA/ASD in IBD. Thus, we believe that this study should initiate a series of investigations in various chronic inflammatory diseases in order to focus on renal excretion of DHEAS.

In conclusion, there is a huge decrease of serum levels of DHEA, DHEAS and ASD in patients with chronic inflammation, which is paralleled by nearly stable serum levels of cortisol. In these patients, it seems as if cortisol secretion is maintained at the expense of ASD, DHEA and DHEAS secretion. In contrast, in patients with an acute inflammatory stressful disease state, there is an increase of all measured adrenal hormones. There are markedly different hormonal response patterns and hormone shifts in patients with an acute inflammatory stressful disease state as compared with patients with chronic inflammation. This study further shows that only TNF is predictive for the modulation of investigated steroid cascades in chronic inflammatory diseases whereas IL-6 is only predictive in patients with an acute inflammatory stressful disease state and in HSs. From this point of view, this study points towards an important role of TNF for changes of steroidogenesis in chronic inflammatory diseases.

\section{Acknowledgements}

We thank Angelika Gräber and Daniela Vogl for technical assistance.

\section{References}

1 Masi AT, Josipovic DB \& Jefferson WE. Low adrenal androgenicanabolic steroids in women with rheumatoid arthritis (RA): gas-liquid chromatographic studies of RA patients and matched normal control women indicating decreased 11-deoxy-17-ketosteroid excretion. Seminars in Arthritis and Rheumatism 1984 $141-23$.

2 Sambrook PN, Eisman JA, Champion GD \& Pocock NA. Sex hormone status and osteoporosis in postmenopausal women with rheumatoid arthritis. Arthritis and Rheumatism 198831 973-978.

3 Deighton CM, Watson MJ \& Walker DJ. Sex hormones in postmenopausal HLA-identical rheumatoid arthritis discordant sibling pairs. Journal of Rheumatology 199219 $1663-1667$.
4 Lahita RG, Bradlow HL, Ginzler E, Pang S \& New M. Low plasma androgens in women with systemic lupus erythematosus. Arthritis and Rheumatism 198730 241-248.

5 Straub RH, Vogl D, Gross V, Lang B, Schölmerich J \& Andus T. Association of humoral markers of inflammation and dehydroepiandrosterone sulfate or cortisol serum levels in patients with chronic inflammatory bowel disease. American Journal of Gastroenterology 199893 2197-2202.

6 de la Torre B, Fransson J \& Scheynius A. Blood dehydroepiandrosterone sulphate (DHEAS) levels in pemphigoid/pemphigus and psoriasis. Clinical and Experimental Rheumatology 199513 345-348.

7 Foppiani L, Cutolo M, Sessarego P, Sulli A, Prete C, Seriolo B et al. Desmopressin and low-dose ACTH test in rheumatoid arthritis. European Journal of Endocrinology 1998138 294-301.

8 Kumpfel T, Then BF, Friess E, Uhr M, Yassouridis A, Trenkwalder $\mathrm{C}$ et al. Dehydroepiandrosterone response to the adrenocorticotropin test and the combined dexamethasone and corticotropin-releasing hormone test in patients with multiple sclerosis. Neuroendocrinology 199970 431-438.

9 Straub RH, Glück T, Cutolo M, Georgi J, Helmke K, Schölmerich J et al. The adrenal steroid status in relation to inflammatory cytokines (interleukin- 6 and tumour necrosis factor) in polymyalgia rheumatica. Rheumatology $200039624-631$.

10 Zietz B, Reber T, Oertel M, Glück T, Schölmerich J \& Straub RH. Altered function of the hypothalamic stress axes in patients with moderately active systemic lupus erythematosus. II. Dissociation between androstenedione, cortisol, or dehydroepiandrosterone and interleukin 6 or tumor necrosis factor. Journal of Rheumatology 200027 911-918.

11 Kanik KS, Chrousos GP, Schumacher HR, Crane ML, Yarboro CH \& Wilder RL. Adrenocorticotropin, glucocorticoid, and androgen secretion in patients with new onset synovitis/rheumatoid arthritis: relations with indices of inflammation. Journal of Clinical Endocrinology and Metabolism 200085 1461-1466.

12 Zietz B, Wengler I, Messmann H, Lock G, Schölmerich J \& Straub RH. Early shifts of adrenal steroid synthesis before and after relief of short-term cholestasis. Journal of Hepatology $20013 \mathbf{5}$ $329-337$.

13 Villette JM, Bourin P, Doinel C, Mansour I, Fiet J, Boudou P et al. Circadian variations in plasma levels of hypophyseal, adrenocortical and testicular hormones in men infected with human immunodeficiency virus. Journal of Clinical Endocrinology and Metabolism $199070572-577$.

14 Parker CR Jr \& Schuster MW. Effects of syphilis infection on adrenocortical function in men. Proceedings of the Society for Experimental Biology and Medicine 1991197 165-167.

15 Moriyama Y, Yasue H, Yoshimura M, Mizuno Y, Nishiyama K, Tsunoda $\mathrm{R}$ et al. The plasma levels of dehydroepiandrosterone sulfate are decreased in patients with chronic heart failure in proportion to the severity. Journal of Clinical Endocrinology and Metabolism 200085 1834-1840.

16 Reincke M, Lehmann R, Karl M, Winkelmann W \& Allolio B. Veränderungen der Nebenierenfunktion bei Schwerstkranken. In Nebeniere und Streß, pp 189-199. Eds B Allolio, G Benker \& HM Schulte. Stuttgart: Schattauer Verlag , 1995.

17 Ohashi M, Kato K, Nawata H \& Ibayashi H. Adrenocortical responsiveness to graded ACTH infusions in normal young and elderly human subjects. Gerontology 198632 43-51.

18 Daidoh H, Morita H, Mune T, Murayama M, Hanafusa J, Ni H et al. Responses of plasma adrenocortical steroids to low dose ACTH in normal subjects. Clinical Endocrinology 199543 311-315.

19 Danenberg HD, Alpert G, Lustig S \& Ben-Nathan D. Dehydroepiandrosterone protects mice from endotoxin toxicity and reduces tumor necrosis factor production. Antimicrobial Agents and Chemotherapy $1992362275-2279$.

20 Di Santo E, Foddi MC, Ricciardi-Castagnoli P, Mennini T \& Ghezzi P. DHEAS inhibits TNF production in monocytes, astrocytes and microglial cells. Neuroimmunomodulation 19963 $285-288$. 
21 Araghi-Niknam M, Zhang Z, Jiang S, Call O, Eskelson CD \& Watson RR. Cytokine dysregulation and increased oxidation is prevented by dehydroepiandrosterone in mice infected with murine leukemia retrovirus. Proceedings of the Society for Experimental Biology and Medicine 1997216 386-391.

22 Kimura M, Tanaka S, Yamada Y, Kiuchi Y, Yamakawa T \& Sekihara H. Dehydroepiandrosterone decreases serum tumor necrosis factor-alpha and restores insulin sensitivity: independent effect from secondary weight reduction in genetically obese Zucker fatty rats. Endocrinology 1998139 3249-3253.

23 Padgett DA \& Loria RM. Endocrine regulation of murine macrophage function: effects of dehydroepiandrosterone, androstenediol, and androstenetriol. Journal of Neuroimmunology 1998 $8461-68$.

24 Wilder RL. Hormones and autoimmunity: animal models of arthritis. Baillieres Clinical Rheumatology $199610259-271$.

25 Greenspan FS. Basic and Clinical Endocrinology. East Norwalk, Connecticut: Appleton and Lange, 1991.

26 Hennebold JD \& Daynes RA. Regulation of macrophage dehydroepiandrosterone sulfate metabolism by inflammatory cytokines. Endocrinology 1994135 67-75.

27 Schmidt M, Kreutz M, Löffler G, Schölmerich J \& Straub RH. Conversion of dehydroepiandrosterone to downstream steroid hormones in macrophages. Journal of Endocrinology $2000 \mathbf{1 6 4}$ 161-169.

28 Rosenfeld RS, Hellman L \& Gallagher TF. Metabolism and interconversion of dehydroisoandrosterone and dehydroisoandrosterone sulfate. Journal of Clinical Endocrinology and Metabolism 197235 187-193.

29 Andus T, Klebl F, Rogler G, Schölmerich J \& Straub RH. Successful treatment of refractory ulcerative colitis with dehydroepiandrosterone (DHEA) - an open controlled pilot trial. Gastroenterology $2000 \mathbf{1 8 8}$ A 116 [Abstract].

30 van Vollenhoven RF, Engleman EG \& McGuire JL. Dehydroepiandrosterone in systemic lupus erythematosus. Results of a double-blind, placebo-controlled, randomized clinical trial. Arthritis and Rheumatism 199538 1826-1831.

31 van Vollenhoven RF, Park JL, Genovese MC, West JP \& McGuire JL. A double-blind, placebo-controlled, clinical trial of dehydroepiandrosterone in severe systemic lupus erythematosus. Lupus $19998181-187$.

32 Arlt W, Callies F, van Vlijmen JC, Koehler I, Reincke M, Bidlingmaier $\mathrm{M}$ et al. Dehydroepiandrosterone replacement in women with adrenal insufficiency. New England Journal of Medicine 1999341 1013-1020.

33 Gebre-Medhin G, Husebye ES, Mallmin H, Helstrom L, Berne C, Karlsson FA et al. Oral dehydroepiandrosterone (DHEA) replacement therapy in women with Addison's disease. Clinical Endocrinology 200052 775-780.

34 Labrie F, Diamond P, Cusan L, Gomez JL, Belanger A \& Candas B. Effect of 12-month dehydroepiandrosterone replacement therapy on bone, vagina, and endometrium in postmenopausal women. Journal of Clinical Endocrinology and Metabolism $1997 \mathbf{8 2}$ 3498-3505.

35 Villareal DT, Holloszy JO \& Kohrt WM. Effects of DHEA replacement on bone mineral density and body composition in elderly women and men. Clinical Endocrinology $200053561-568$.

36 Ellstrom M, Bengtsson A, Tylman M, Haeger M, Olsson JH \& Hahlin M. Evaluation of tissue trauma after laparoscopic and abdominal hysterectomy: measurements of neutrophil activation and release of interleukin-6, cortisol, and C-reactive protein. Journal of the American College of Surgeons 1996182 423-430.

37 Ueo H, Inoue H, Honda M, Uchida I, Nishimura M, Arinaga S et al. Production of interleukin-6 at operative wound sites in surgical patients. Journal of the American College of Surgeons 1994179 326-332.

38 Seitz W, Luebbe N, Bechstein W, Fritz K \& Kirchner E. A comparison of two types of anaesthesia on the endocrine and metabolic responses to anaesthesia and surgery. European Journal of Anaesthesiology $19863283-294$.
39 Stahl F, Schnorr D, Pilz C \& Dorner G. Dehydroepiandrosterone (DHEA) levels in patients with prostatic cancer, heart diseases and under surgery stress. Experimental and Clinical Endocrinology $19929968-70$.

40 Eriksson-Mjoberg M, Olund A \& Carlstrom K. Hormonal patterns in postmenopausal women during gynecological surgery. Gynecologic and Obstetric Investigation 199743 41-46.

41 Straub RH, Konecna L, Hrach S, Rothe G, Kreutz M, Schölmerich J et al. Serum dehydroepiandrosterone (DHEA) and DHEA sulfate are negatively correlated with serum interleukin-6 (IL-6), and DHEA inhibits IL-6 secretion from mononuclear cells in man in vitro: possible link between endocrinosenescence and immunosenescence. Journal of Clinical Endocrinology and Metabolism $1998832012-2017$.

42 Ligthart GJ, Corberand JX, Fournier C, Galanaud P, Hijmans W, Kennes B et al. Admission criteria for immunogerontological studies in man: the SENIEUR protocol. Mechanisms of Ageing and Development $1984 \mathbf{2 8} 47-55$.

43 van Hees PA, van Elteren PH, van Lier HJ \& van Tongeren JH. An index of inflammatory activity in patients with Crohn's disease. Gut $198021279-286$.

44 Rachmilewitz D. Coated mesalazine (5-aminosalicylic acid) versus sulphasalazine in the treatment of active ulcerative colitis: a randomised trial. British Medical Journal 1989298 82-86.

45 Kern JA, Lamb RJ, Reed JC, Daniele RP \& Nowell PC. Dexamethasone inhibition of interleukin 1 beta production by human monocytes. Posttranscriptional mechanisms. Journal of Clinical Investigation $1988 \mathbf{8 1} 237-244$.

46 Karck U, Peters T \& Decker K. The release of tumor necrosis factor from endotoxin-stimulated rat Kupffer cells is regulated by prostaglandin E2 and dexamethasone. Journal of Hepatology 19887 352-361.

47 Spencer NF, Poynter ME, Im SY \& Daynes RA. Constitutive activation of NF-kappa B in an animal model of aging. International Immunology $199791581-1588$.

48 Poynter ME \& Daynes RA. Peroxisome proliferator-activated receptor alpha activation modulates cellular redox status, represses nuclear factor-kappaB signaling, and reduces inflammatory cytokine production in aging. Journal of Biological Chemistry $199827332833-32841$.

49 Munck A \& Guyre PM. Glucocorticoid physiology, pharmacology and stress. Advances in Experimental Medicine and Biology 1986 $19681-96$.

50 Jaques $\mathrm{R} \&$ Jaquet $\mathrm{H}$. The duration of action of certain corticosteroids in the acutely adrenalectomized rat as estimated by reference to their protective effect in endotoxin shock. Experientia $196420230-231$.

51 Fukuda T \& Hata N. Mechanisms of endotoxin shock in rats and the anti-endotoxic effect of glucocorticoids and endotoxin-conditioning. Japanese Journal of Physiology $196919509-520$.

52 Hinshaw LB, Beller BK, Chang AC, Murray CK, Flournoy DJ, Passey RB et al. Corticosteroid/antibiotic treatment of adrenalectomized dogs challenged with lethal E. coli. Circulatory Shock $198516265-277$.

53 Bertini R, Bianchi M \& Ghezzi P. Adrenalectomy sensitizes mice to the lethal effects of interleukin 1 and tumor necrosis factor. Journal of Experimental Medicine 1988167 1708-1712.

54 Straub RH, Zeuner M, Antoniou E, Schölmerich J \& Lang B. Dehydroepiandrosterone sulfate is positively correlated with soluble interleukin 2 receptor and soluble intercellular adhesion molecule in systemic lupus erythematosus. Journal of Rheumatology $1996 \mathbf{2 3}$ 856-861.

55 Mauduit C, Gasnier F, Rey C, Chauvin MA, Stocco DM, Louisot P et al. Tumor necrosis factor-alpha inhibits Leydig cell steroidogenesis through a decrease in steroidogenic acute regulatory protein expression. Endocrinology $19981392863-2868$.

56 Lin T, Hu J, Wang D \& Stocco DM. Interferon-gamma inhibits the steroidogenic acute regulatory protein messenger ribonucleic acid expression and protein levels in primary cultures of rat Leydig cells. Endocrinology $19981392217-2222$. 
57 Budnik LT, Jahner D \& Mukhopadhyay AK. Inhibitory effects of TNF alpha on mouse tumor Leydig cells: possible role of ceramide in the mechanism of action. Molecular and Cellular Endocrinology $199915039-46$.

58 Ogilvie KM, Held HK, Roberts ME, Hales DB \& Rivier C. The inhibitory effect of intracerebroventricularly injected interleukin 1beta on testosterone secretion in the rat: role of steroidogenic acute regulatory protein. Biology of Reproduction $1999 \mathbf{6 0}$ $527-533$

59 Jäättelä M, Ilvesmaki V, Voutilainen R, Stenman UH \& Saksela E. Tumor necrosis factor as a potent inhibitor of adrenocorticotropin-induced cortisol production and steroidogenic P450 enzyme gene expression in cultured human fetal adrenal cells. Endocrinology $1991 \mathbf{1 2 8} 623-629$.

60 Lin T, Wang TL, Nagpal ML, Calkins JH, Chang WW \& Chi R Interleukin-1 inhibits cholesterol side-chain cleavage cytochrome P450 expression in primary cultures of Leydig cells. Endocrinology $19911291305-1311$.

61 Orava M, Voutilainen R \& Vihko R. Interferon-gamma inhibits steroidogenesis and accumulation of mRNA of the steroidogenic enzymes P450scc and $\mathrm{P} 450 \mathrm{c} 17$ in cultured porcine Leydig cells. Molecular Endocrinology 19893 887-894.

62 Päth G, Bornstein SR, Späth-Schwalbe E \& Scherbaum WA. Direct effects of interleukin-6 on human adrenal cells. Endocrine Research $199622867-873$.

63 Judd AM \& MacLeod RM. Differential release of tumor necrosis factor and IL-6 from adrenal zona glomerulosa cells in vitro. American Journal of Physiology 1995268 E114-E120.

64 Gonzalez-Hernandez JA, Ehrhart-Bornstein M, Spath-Schwalbe E, Scherbaum WA \& Bornstein SR. Human adrenal cells express tumor necrosis factor-alpha messenger ribonucleic acid: evidence for paracrine control of adrenal function. Journal of Clinical Endocrinology and Metabolism 199681 807-813.

Received 27 July 2001

Accepted 9 November 2001 